\title{
Use of real-time B-mode ultrasound for pregnancy diagnosis and measurement of fetal growth rate in captive bottlenose dolphins (Tursiops truncatus)
}

\author{
P. Williamson*, N. J. Gales† and S. Lister* \\ * School of Veterinary Studies, Murdoch University, Perth, Western Australia 6150, Australia; and \\ $\dagger$ Atlantis Marine Park, Two Rocks, Perth, Western Australia 6037, Australia
}

\begin{abstract}
Summary. Real-time ultrasonography was used to detect pregnancy in 4 captive bottlenose dolphins. Pregnancy was readily confirmed from around the 4th month of gestation by imaging fetal fluids and fetal movement. Periodic examination permitted monitoring of the viability of the fetuses by observation of their heart beat and movement, and serial measurements of skull diameter (occipito-frontal axis) and thoracic diameter was possible. A growth curve for these measurements was plotted.
\end{abstract}

Keywords: bottlenose dolphin; pregnancy diagnosis; real time ultrasound; fetal growth rate; reproduction

\section{Introduction}

The bottlenose dolphin (Tursiops truncatus) is the most common dolphin species held in marine parks world-wide, and it has been bred successfully in captivity (Amundin, 1986; Yoshioka et al., 1986; Cornell et al., 1987).

Wild bottlenose dolphins breed predominantly in spring and autumn and pregnancy lasts between $11 \frac{1}{2}$ and 12 months (Essapian, 1963; Harrison, 1969; Cornell et al., 1987), with a calving interval of 2-3 years (Kasuya, 1985). Observations on captive populations indicate that females first breed at around 9-10 years of age and have been recorded as pregnant at 23 years (Cornell et al., 1987). Pregnancy has been diagnosed in bottlenose dolphins by increased abdominal roundness from 4 months of pregnancy, mammary gland development from 7 months and straining and body flexion with laboured respiration in late pregnancy (McBride \& Kritzler, 1951; Tavolga \& Essapian, 1957). Cornell et al. (1987) reported that fetal heart beats could be reliably located by Doppler stethoscope from 4-5 months of gestation, and that pregnancy could be accurately diagnosed when serum progesterone concentrations exceeded $6 \mathrm{ng} / \mathrm{ml}$ for a 4-6-week period. These authors also reported the use of real-time $B$-mode ultrasound to detect pregnancy and monitor fetal development, although little information on its efficacy or accuracy was provided.

In June 1988 staff at Atlantis Marine Park, Western Australia, noted weight increases in 2 of the 4 female bottlenose dolphins during routine monthly weighings. Real-time B-mode ultrasound imaging was therefore undertaken to determine whether the weight gain in the females was due to pregnancy. This technique was chosen as it is non-invasive and provides evidence of fetal viability.

\section{Materials and Methods}

The marine park $\left(80 \mathrm{~km}\right.$ north of Perth, $\left.32^{\circ} \mathrm{S}\right)$ had 4 female bottlenose dolphins (estimated to be $11-14$ years old using length as an approximate age index). They occupied a large salt water pool $\left(1200 \mathrm{~m}^{3}\right)$ with 3 male cohorts and have done so since capture in 1981 . No information was available on the ultrasonic anatomy of dolphins, and so 2 of the males were examined by ultrasound for comparison. The dolphins were trained to lie upside down in the water to 
allow imaging of the ventral abdomen. The dolphins maintained this position for $15-30 \mathrm{sec}$ before rotating upright to breathe. The procedure was repeated 34 times with each dolphin at each examination until 2-3 months before parturition, when the dolphins became reluctant to assume the supine position. Imaging was performed at approximately monthly intervals using an Aloka SSD260 ultrasound machine (Aloka Company, Tokyo, Japan) with a 3.5 MHz linear array transducer (Aloka UST-5021). The transducer was enclosed within a thin plastic sleeve (to protect it against salt water) and copious amounts of contact gel were used to provide a good contact. Imaging was performed with the dolphin's right side adjacent to the edge of the pool, as Slipjer (1962) reported that $83 \%$ of pregnancies in delphinids occurred in the left horn of the uterus. Initially, transverse images were obtained by placing the transducer on the midline between the genital slit and the umbilicus. Later in pregnancy the transducer was placed longitudinally along the left flank, $10-20 \mathrm{~cm}$ from the midline. All images were recorded on video. At least two measurements were made of the identified fetal structures by matching diameters or widths against the on-screen ultrasound scale. Measurements were taken of thoracic cross-sections at the 2 nd or 3rd intercostal space (maximum diameter of the heart), skull diameters, rib and thoracic vertebral widths and rostral length. A total of 8 examinations was undertaken on each of the female dolphins at various stages of pregnancy.

\section{Results}

Dolphins R, M and K gave birth to live calves on 4 January 1989, 7 March 1989 and 26 April 1989 respectively. Dolphin L produced a stillborn calf $(97 \mathrm{~cm}$ long, $10 \mathrm{~kg}$ weight) on 28 November 1988. At examination on 8 November, the fetus of Dolphin $\mathrm{L}$ was viable and had grown from the previous examination.

The fetal fluids and the fetus were readily recognized in the pregnant dolphins. The earliest fetal image was seen in Dolphin K, 35 weeks before parturition, whereas at examination 5 weeks previously no fetus was imaged. This may have been due to inexperience with the technique. The other pregnant dolphins were beyond this stage of pregnancy at the first examination.

Fetal heart beats were regularly imaged and indicated continued viability of the fetus. Other fetal structures were difficult to image due to the brief time available for placement of the transducer. However, over the series of examinations sufficient images were obtained of the diameter of the thorax (Fig. 1a; 17 observations) and of the skull diameter (occipito-frontal axis, Fig. 1c; 8 observations) for composite growth patterns to be plotted. Other structures, such as the length from the tip of the rostrum to the orbit (Fig. 2) and the width across the first 3 ribs (Fig. 3), did not give reliable measurements. Mating had been observed over an extended period through summer and autumn (December to March) and so dates of conception were not known. Measurements from the 3 dolphins which gave birth to live calves were therefore plotted against the interval from the time when the measurement was recorded to parturition (Figs $4 \mathrm{a} \& 4 \mathrm{~b}$ ). A simple regression was applied to the data, as the parameters measured are known to increase linearly as pregnancy progresses in humans (Kurtz \& Needleman, 1988).

Fetal measurements recorded from Dolphin L before the abortion were compared with those from the other dolphins. An estimate of the time when a normal parturition would have occurred was made, and this indicated that abortion had occurred approximately 11 weeks (skull diameter measurements) to 9 weeks (thoracic diameter measurements) before full term.

\section{Discussion}

Real-time B-mode ultrasound imaging provided a reliable non-invasive means of pregnancy diagnosis in all 4 dolphins. There was clear evidence of fetal viability from approximately the 4 th month of pregnancy onwards. The serial measurement of serum progesterone concentrations provides an accurate means of pregnancy detection in dolphins, earlier than the results achieved with ultrasonography in the present study (Cornell et al., 1987). However, blood sampling is invasive and progesterone concentrations give no direct indication of the viability of the fetus. Two limitations were encountered in the present study. Firstly, during late pregnancy imaging was difficult since the dolphins would not present themselves for examination. In addition, the ultrasound machine used 

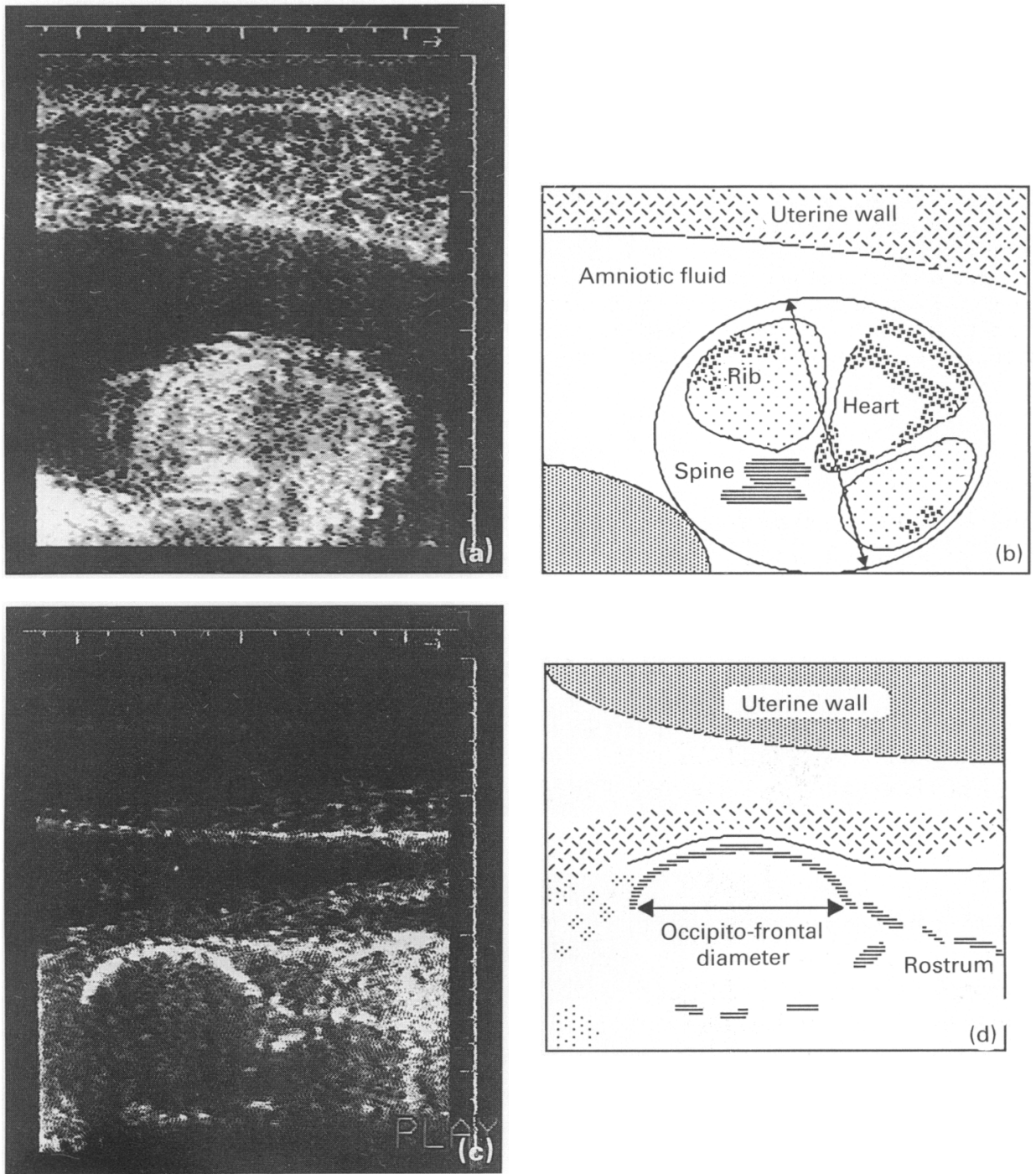

Fig. 1. Ultrasound measurements of $(a, b)$ thoracic diameter and $(c, d)$ skull diameter in fetal dolphins. (a, b) Transverse section of the fetal thorax at the approximate level of the $2 \mathrm{nd}$ or $3 \mathrm{rd}$ intercostal space (Dolphin K, 17 weeks before birth). Measurements of thoracic diameters were taken on the narrowest axis. (c, d) Median section of the fetal skull (Dolphin K, 26 weeks before birth). Measurements of skull diameters were taken along the occipito-frontal axis.

in the present study was not capable of imaging to a depth adequate for measurement of fetal thoracic diameter in late pregnancy.

Diagnostic ultrasound allows the serial measurement of fetal structures such as skull and thoracic diameters, and enables monitoring of fetal growth rate. Ultrasound has been widely used for monitoring fetal growth and viability in humans; biparietal skull diameter and abdominal circumference provide the most reliable estimate of fetal age (Hadlock et al., 1982). These measurements allow the prediction of birth dates to within 5-7 days when measured in the first trimester and 2-4 weeks when measured in the third trimester of pregnancy (Kurtz \& Needleman, 1988). Both measurements show linear growth for the normal human fetus. Similarly, Laws (1959) reported linear growth of fetal length through gestation in odontocetes, based on direct measurement. More 

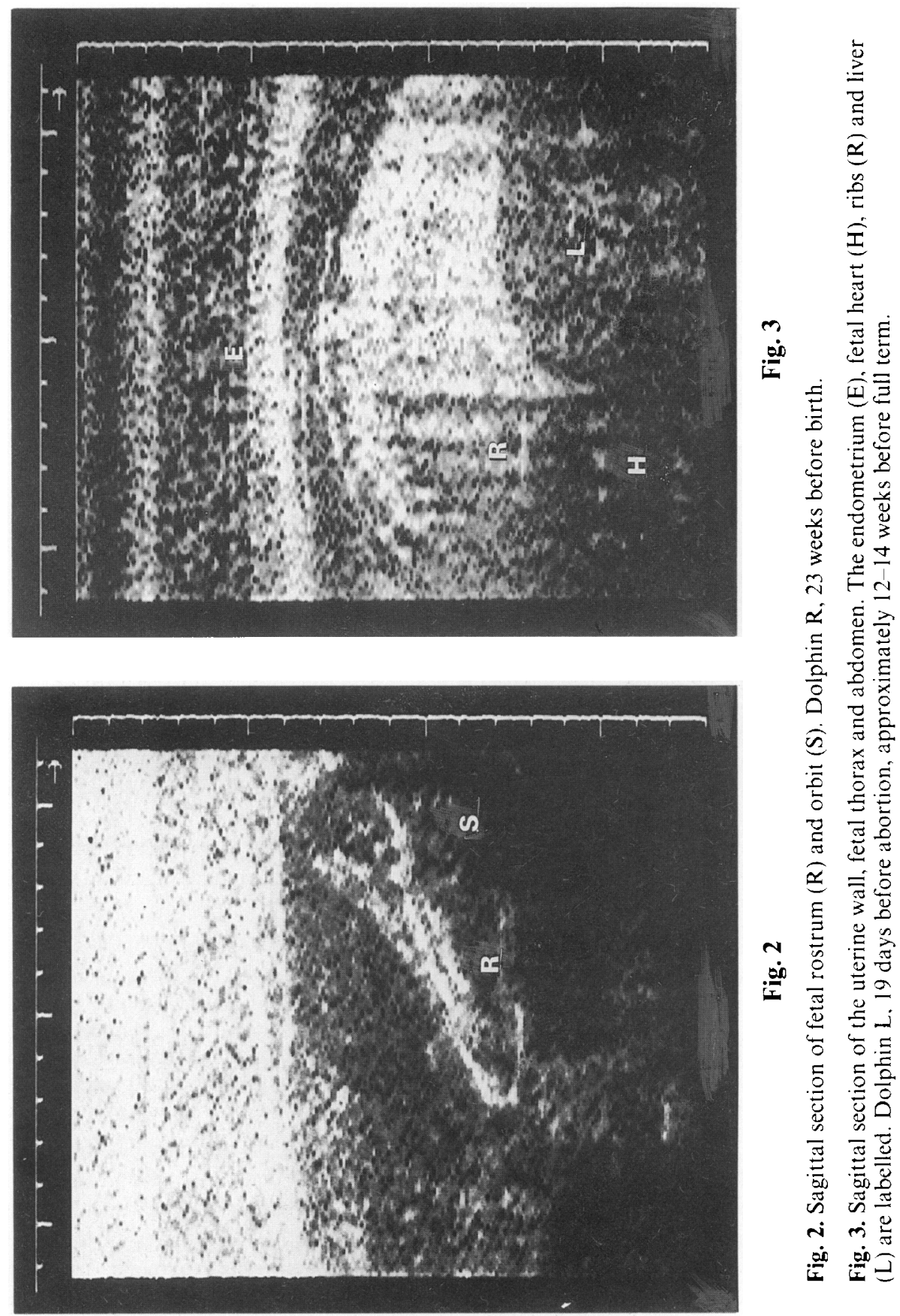

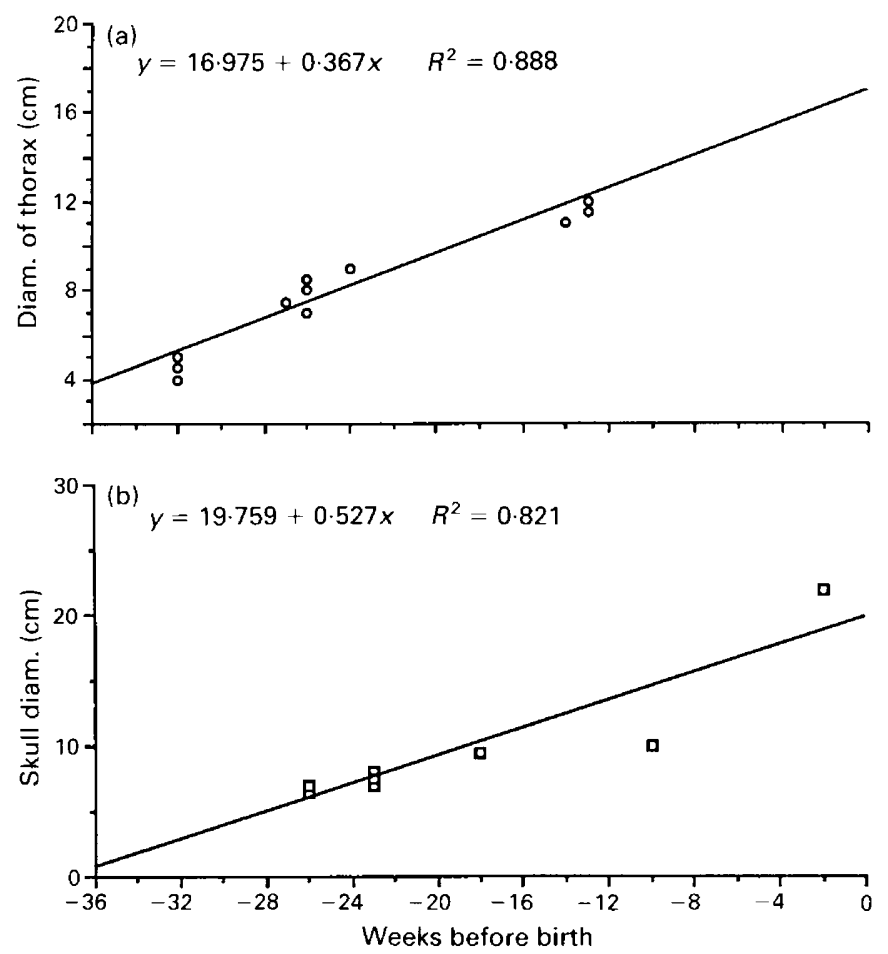

Fig. 4. Diameters of (a) fetal thorax and (b) skull (occipito-frontal diameter) of fetal dolphins measured from ultrasound images recorded at successive examinations in dolphins which gave birth to live calves, and plotted against the interval from the examination to parturition.

4data from real-time ultrasound studies are required to test the accuracy and linearity of the regression lines found in the present study. However, they do provide a guide to growth rates.

We thank the management and mammal-keeping staff at Atlantis Marine Park for support and expert help; James Murray for technical assistance; and the ultrasonography staff at King Edward Memorial Hospital, Perth, for valuable advice.

\section{References}

Amundin, M. (1986) Breeding the bottle-nose dolphin Tursiops truncatus at the Kolmarden Dolphinarium. Int. Zoo Yb. 24/25, 263-271.

Cornell, L.H., Asper, E.D., Antrim, J.E., Searles, S.S., Young, W.G. \& Goff, T. (1987) Progress report: Results of a long-range captive breeding program for the bottle-nose dolphin Tursiops truncatus and Tursiops truncatus-gilli. Zoo Biol. 6, 41-54.

Essapian, F.S. (1963) Observations on abnormalities of parturition in captive bottle-nosed dolphins, Tursiops truncatus, and concurrent behaviour of other porpoises. J. Mammal. 44, 405-413.

Hadlock, F.P., Deter, R.L., Harrist, R.B. \& Park, S.K. (1982) Fetal biparietal diameter: rational choice of plane of section for sonographic measurement. $\mathrm{Am}$. J. Roent. 138, 871-874.

Harrison, R.J. (1969) Reproduction and reproductive organs. In The Biology of Marine Mammals, pp. 253 348. Ed. H. T. Anderson. Academic Press, London.

Kasuya, T. (1985) Effect of exploitation on reproductive parameters of the spotted and striped dolphins off the Pacific Coast of Japan. Sci. Rep. Whales Res. Inst. Tokyo 36, 107-138.

Kurtz, A.B. \& Needleman, L. (1988) Ultrasound assessment of fetal age. In: Ultrasonography in Obstetrics and Gynecology, 2nd edn, pp. 47-64. Ed. P. W. Callen. W.B. Saunders Company, Philadelphia.

Laws, R.M. (1959) The foetal growth rates of whales with special reference to the Fin whale, Balaenoptera physalus Linn. 'Discovery' Rep. 29, 281-308.

McBride, A.F. \& Kritzler, H. (1951) Observations on pregnancy, parturition and post-natal behaviour in the bottlenose dolphin. J. Mammal. 32, 251-266.

Slipjer, E.J. (1962) Whales. Hutchinson, London. 
Tavolga, M.C. \& Essapian, F.S. (1957) The behaviour of the bottle-nose dolphin (Tursiops truncatus); Mating, pregnancy, parturition and mother-infant behaviour. Zoologica, NY 42, 11-31.
Yoshioka, M., Mohri, E., Tobayama, T., Aida, K. \& Hanyu, I. (1986) Annual changes in serum reproductive hormone levels in captive female bottle-nosed dolphins. Bull. Jap. Soc. Sci. Fish. 52, 1939-1946.

Received 13 June 1989 